\title{
Thematic Structure and Its Application to English Writing
}

\author{
Dan Fang \\ School of Foreign Languages of University of Jinan \\ Jinan, China \\ 18766122644@163.com
}

\author{
Shuxiang Li \\ School of Foreign Languages of University of Jinan \\ Jinan, China \\ 565836562@qq.com
}

\begin{abstract}
Writing is an essential part of English learning in college. As a result, how to improve the writing standard has become one of the major topics in English learning. The thematic structure, especially patterns of thematic progression plays an important role in cohesion and coherence of writing. This thesis illustrates the necessity of thematic structure in college English writing in the theoretical and practical perspectives. In theory, thematic structure can be used not only to analyze the passage as a whole, but also to make it easy to grasp the main idea. In practice, the English writing in college focuses more on the clear and well-organized structure than correct grammar and wide vocabulary. Then this thesis proposes some strategies to improve English from the perspective of thematic structure, which tends to give some enlightenment to students in college.
\end{abstract}

Keywords-thematic structure; patterns of thematic progression; college English writing

\section{INTRODUCTION}

Writing, as one of the basic skills in the study of English, plays an increasingly important role in English learning, especially for most students in college facing the examinations such as CET-4 and CET-6. Therefore, there are different theories and methods to improve students' writing among which the thematic structure has a big influence.

On the basis of thematic structure, this thesis aims to make clear two points: (1) What are the key points in thematic structure? (2) How does this theory apply to English writing? In this thesis, a brief introduction to Theme and Rheme is made at first. Then an attempt is made to illustrate the patterns of thematic progression. Finally, after analysis of the problems in students' writing, some sample writings are analyzed based on the thematic progression.

\section{GENERAL InTRODUCTION OF THEME AND RHEME}

\section{A. Identification of Theme and Rheme}

It was Mathesius, one of the founders of the Prague School, who first put forward the concept of Theme and Rheme in 1930s in order to distinguish traditional terms of the "subject" and "predicate" on the level of grammar. He thought that Theme is known message and serves as the starting point of a sentence to lead to the topic in the process of communication. As for other elements, they are Rheme and new messages. Later, the representative figure of the systemic-functional school, Halliday, has accepted the concept of Theme and Rheme and further developed this theory. He divided Theme into three types, simple Theme, clause Theme, and multiple Theme.

Theme is the first constituent of the clause which serves as a starting point of expression and reflects the information that has already been known to the speakers in the context. And all the rest of the clause is simply labelled as Rheme which is the core of expression in the sentences. See table 1.

TABle 1 Theme And RhemeTABle Type Styles

\begin{tabular}{|c|l|}
\hline The cartoon & $\begin{array}{l}\text { tells us that being optimistic and } \\
\text { being pessimistic are two different } \\
\text { attitudes towards life. }\end{array}$ \\
\hline Theme & Rheme \\
\hline
\end{tabular}

\section{B. Classification of Theme}

This thesis will divide Theme into three parts in agreement with Halliday's view, and multiple Theme includes textual Theme and interpersonal Theme as well as experiential Theme.

1) Simple Theme: Simple Theme refers to the Theme only consisting of one structural element, such as a word, a phrase, or a group and it cannot be divided in the internal structure. See table 2.

TABle 2 Simple Theme

\begin{tabular}{|c|l|}
\hline The duke & has given my aunt that teapot. \\
\hline Simple Theme & Rheme \\
\hline 2) Clause Theme: Just as the name shows, a clause
\end{tabular}
serves as Theme here, either main clause or subordinate clause. In addition, the internal structure of the clause Theme can be divided into another Theme and Rheme. See table 3.

TABLE 3

Clause Theme TABle

\begin{tabular}{|c|c|}
\hline What I'm going to do now & is to whisk these all together. \\
\hline Clause Theme & Rheme \\
\hline
\end{tabular}

3) Multiple Theme: Just as the name shows, a clause serves as Theme here, either main clause or subordinate clause. 
In addition, the internal structure of the clause Theme can be divided into another Theme and Rheme. See table 3. If Theme includes two or more structural elements, it is called multiple Theme, including textual Theme, interpersonal Theme and experiential Theme. Besides, there is an order among these three elements, namely, textual Theme, interpersonal Theme and experiential Theme, one Theme following another. Further more, every clause must have one, and only one, "experiential" element to act as the Theme (Eggins: 1994:277). If there is the simple Theme in a clause, it is the experiential element. And multiple Theme must include one, and only one element to express the experiential meaning, but it can cover more than one textual elements and interpersonal elements.

We can see the following table 4 as the example of multiple Theme.(Thompson 2004:159)

TAble 4 Multiple Theme Table

\begin{tabular}{|l|l|l|l|}
\hline Well, & $\begin{array}{l}\text { certainly, } \\
\text { My God, Harriet }\end{array}$ & $\begin{array}{l}\text { sanity } \\
\text { we } \\
\text { But } \\
\text { And, } \\
\text { surely } \\
\text { he course }\end{array}$ & $\begin{array}{l}\text { is a precarious state. } \\
\text { ve' been dealt a bad hand! } \\
\text { doesn't start till next week. } \\
\text { was right. }\end{array}$ \\
\hline textual & interpersonal & experiential & \multirow{2}{*}{ Rheme } \\
\hline \multicolumn{2}{|l|}{ Theme } & & Ren \\
\hline
\end{tabular}

\section{Thematic Structure}

As we know from the above analysis, a clause is supposed to include two parts. One is Theme, and the other is Rheme. Theme is what the clause is concerned; it is the element that serves as the start of a clause. Following Theme, Rheme further explains what Theme is about to make the clause complete in structure. Thus, in a clause, the thematic structure is always expressed by the order, namely, Theme is put in the first place.

In addition, people are accustomed to talking with other from the known message to the new. Theme, as the starting point of the message, is already known by the speakers and hearers. Based on this, it is possible for Rheme to convey the new information. At last, the clause can express the integrated meaning. From this point, the thematic structure in a clause can be considered to push ahead with the communication smoothly.

\section{PATterns of Thematic Progression AND Their SIGNIFICANCE}

Every sentence has its own thematic structure. When a sentence exists alone, its Theme and Rheme are certain and cannot develop because it has no context. However, almost all the texts are made up of two or more sentences. At that time, there are some connections and changes between Themes and Rhemes, which are called progression. As Themes in every sentence push ahead, the whole text gradually unfolds until it forms the complete meaning.

There are a variety of discourses in English writing. Due to different writing materials, the themes are changeable frequently. And the length of a piece of writing and types of literature have an influence on the structure and degree of difficulty of writing. As a result, people have many choices to determine what can be seen as Theme, but in fact it is limited to a great extent. Finally, after some researches, some linguists summarized (Danes:1974; Fries:1983) the basic types about how Theme changes and called them patterns of thematic progression.

In this thesis, five types of the commonest patterns will be analyzed.

\section{A. Pattern of Parallel Progression}

The two adjoining sentences have the same Theme, but different Rhemes. This type of pattern can be indicated as:

\section{T1}

$\mathrm{T} 2(=\mathrm{T} 1) \quad \mathrm{P} 2$

$\nabla$

$\mathrm{T} 3(=\mathrm{T} 1=\mathrm{T} 2) \quad \mathrm{P} 3$

e.g. Jim(T1) is a good student(R1). He(T2) goes to school by bike(R2). And he(T3) likes to help others(R3).

There is anther special pattern in this category, called the Derived Theme Pattern. That means that the Themes of the following sentences are parts of the Theme in the first sentence. This type of pattern can be indicated as:

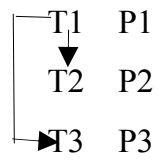

e.g. We (T1) were discussing where to go for an outgoing(R1). Some(T2) suggested the Guanting Reservoir(R2). Others(T3) wanted to see the Great Wall(R3).

\section{B. Pattern of Concentrated Progression}

The two adjoining sentences have the same Rheme, but different Themes. This type of pattern can be indicated as:

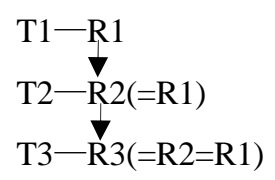

e.g. Linda(T1) likes the diamond(R1). Mary(T2) likes the diamond(R2). Anna(T3) likes the diamond(R3). All(T4) the ladies like the diamond(R4).

\section{Pattern of Continuous Progression}

The Rheme of the former sentence is the Theme of the following one. This type of pattern can be indicated as:

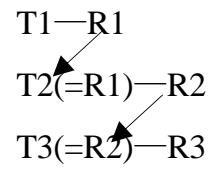

e.g. An English teacher(T1) usually divides her time among three subjects: language, composition and literature(R1). Mrs. Cox's favourite subject(T2) is literature(R2), and her most 
exciting literature classes(T3) are those on the literature of Black Americans(R3).

\section{Pattern of Concentrated Progression}

The Theme of the former sentence is the Rheme of the following one. This type of pattern can be indicated as:<smiles>[R17][R]([H])([AlH])[Te]</smiles>

e.g. The play(T1) was interesting(R1), but I(T2) didn't enjoy it(R2). A young man and a young woman(T3) troubled me(R3). I(T4) turned around and looked at them(R4), but they(T5) didn’t pay any attention to me(R5).

\section{E. Pattern of Concentrated Progression}

he Themes in odd sentences are the same, so are those in even sentences. This type of pattern can be indicated as:

$$
\left[\begin{array}{l}
\mathrm{T} 1-\mathrm{R} 1 \\
\mathrm{~T} 2-\mathrm{R} 2 \\
\mathrm{~T} 3(=\mathrm{T} 1)-\mathrm{R} 3 \\
\mathrm{~T} 4(=\mathrm{T} 2)-\mathrm{R} 4
\end{array}\right.
$$

e.g. People in cities(T1) are much more careful to respect the privacy of the individual(R1). Villagers and farmers(T2) are likely to show a great deal of interest in the lives of others(R2). People in cities(T3) have more opportunities(R3). Villagers and farmers(T4) sometimes have to go to cities to seek jobs(R4).

From the above analysis, it's obvious that complex context structure doesn't only remain the simple progression pattern in a simple, neat and ordered way. In most cases, it always emerges in many mixed forms and produces more complicated forms like coordination, contrast, derivation, etc. As a matter of fact, it is very rare to see that the whole text uses one single progression pattern, but it is common that different kinds of patterns push ahead with the development of the context.

\section{RELATIONSHIP BETWEEN PATTERNS OF THEMATIC PROGRESSION AND ENGLISH WRITING}

Firstly, the patterns of thematic progression can increase the logic in writing.

As we mentioned above, the patterns of progression are complicated. And different ones are included in most discourses, so when it comes to a discourse, we firstly find out Theme and Rheme, further summarize the thematic progression according to the sequence of sentences and then we can understand the writer's thought, which makes the discourse more logical.

When writing, we can make full use of thematic progression to better arrange the structure on a whole and have a good idea of what to express at first, how to transfer one subject to another and what to put in the end. Only by this means can the passage develop in a well-organized way and readers follow the clues of the writing.
Secondly, they can enhance coherence in the passage.

As one of the most important features in a discourse, coherence has been paid more attention to. In traditional writing, we often use grammar and vocabulary to increase coherence, such as pronoun, conjunction, transitional words, etc. Although these are necessary in writing, they cannot guarantee enough coherence in a discourse. As we analyze above, thematic progression has a direct influence on coherence. In other words, we can learn to focus on the structure as a whole instead of some words to make the passage coherent by understanding the laws of thematic progression.

The thematic progression places more emphasis on the relationship between Themes and Rhemes. The development of Rheme is in accordance with the progression of Theme. Theme in the former sentence may become Theme or Rheme in the latter sentence. As this recurrence moves on, the writing appears to be compact in structure and every sentence relates to each other closely. As a result, the coherence in a discourse can be improved.

Thirdly, different patterns are applied to different literary genres.

Patterns of thematic progression have a close relationship with literary genres. For example, the patterns in an expository discourse are different from those in a narrative discourse. In an expository discourse, every sentence is connected with proceeding context logically and serves as the extension of it. Therefore, we always choose the Rheme in former sentence as the Theme of the new one, which leads to much usage of continuous progression. On the contrary, in a narrative discourse, each sentence puts the characters, time, and places as the starting point, so it tends to adopt more parallel progression. In another word, we use different patterns of thematic progression in different literary genres.

\section{ApPliCATION OF THEMATIC STRUCtURE TO ENGLiSH WRITING}

\section{A. Sample Analysis}

From the above discussion, we have already known the five basic patterns of progression. In this part, sample writings will be analyzed.

This is a model essay from CET-4.

When it comes to choosing teachers, students(T1) often take three major factors into consideration(R1). First of all, they(T2) are convinced that teachers should be knowledgeable and should be experts in the fields they teach(R2). Moreover, they(T3) think teaching methods and skills are essential to a good teacher(R3). In addition, the teachers' sense of hurmor(T4) often plays an important role in being chosen by students(R4).

The thematic progression in this sample writing can be indicated as:

$$
\begin{aligned}
& \mathrm{T} 1-\mathrm{R} 1 \\
& \mathrm{~T} 3(=\mathrm{T} 1=\mathrm{T} 2)-\mathrm{R} 3
\end{aligned}
$$

In this part, "students" in the first sentence is the same as 
"they" in the following two sentences, which shows that the first three adjoining sentences have the same Theme, but their Rhemes are different, so they form the pattern of parallel progression. This paragraph mainly talks about students' three factors to choose teachers, so "students" must be highlighted. Then the Rhemes develop around the "students" and give new messages, which further explain what kinds of factors students consider when they choose teachers. On the one hand, students consider teachers' professional knowledge. On the other hand, they pay more emphasis on the methods of teaching. The reason why it uses parallel progression is that the topic can be brought into bold relief.

\section{Sample writing 2 is from a student's writing from CET-4:}

Firstly, hiring cleaners(T1) will cost a lot of money(R1). Most college students(T2) don't have a job(R2). Their parents(T3) pay for their expense(R3). Hiring cleaners (T4) absolutely increases parents' burdens(R4). In addition, hiring cleaners(T5) is not as secure as we expect(R5). Permitting strangers into the dormitory(T6) may result in some pilferage(R6). Furthermore, other members living in the dormitory(T7) may not want to accept it(R7). The last but most important, the college students(T8) may become not only lazy but also dependent because of hiring cleaners(R8).

The thematic progression in this sample writing can be indicated as:

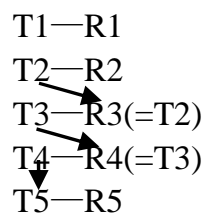

Here we mainly focus on the pattern of progression in the first four sentences. As we can know from the analysis we have made, the second, third and fourth sentence connect closely with each other. T2 "Most college students" becomes R3 in the following sentence. Furthermore, T3 "their parents" is referred to R4. Therefore, this recurrence increases the coherence in the passage. But the first two sentences seem to have no close relation to each other. If we change the second sentence into "Most college students don't have their own money to hire cleaners", R2 has relationship with T1. Then sentence one to sentence four form a pattern, which is intersectional progression. So the thematic progression can be indicated as:

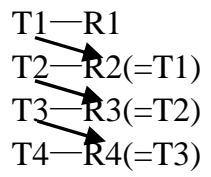

This part uses pattern of intersectional progression and this progression makes the passage more coherent and compact in structure.

\section{B. Application in English Writing Teaching}

It's a common phenomenon among students that they have no idea of what to write after just writing few sentences. One of the main reason is that they don't know how to analyze materials. Generally speaking, teachers always ask students to apply sentence structures and usage of words mechanically. However, if students are not taught how to organize sentences so that only sporadic sentences are left, it is difficult for them to form the coherent discourse although they master lots of materials.

Just take sample writing 1 from CET- 4 as an example. If teachers only teach some usage of words or sentence structures in this passage, students may be skilled in writing certain sentence with these methods, but they cannot apply these sentences to a coherent discourse. In addition to these methods, teachers should introduce more ways to ensure that students have something to write and know how to write logically. As we have discussed, the thematic progression can realize this goals. Therefore, teachers can guide students to analyze the Themes in this passage and try to understand how the writer organize the passage: the main part develop from the point of "students", and further explain what "they" consider when choosing teachers. Then students find that all Themes are identical and the rest part of sentences explain the Theme from different aspects. At this time, teachers can tell students that in this way the whole passage has clear logic and they can make full use of the materials to write the passage around the Theme. After that, teachers can introduce the relationship among sentences to students, which is called "parallel progression" and further introduce more patterns of thematic progression so that they can use this methods consciously when writing.

\section{CONCLUSION}

This paper focuses on the thematic structure and its application to English writing. The Theme-Rheme theory and the thematic progression are two key issues in thematic structure. With the discussion about them, we can see that they play an indispensable part in the organization of structures and cohesion and coherence in the passage. Besides, we acquire more measures to get over the existing problems in students' writing.

English writing is a heatedly discussed topic. This paper just makes a skin-deep study of it. More studies should be carried out in order to explore the practical strategies.

\section{REFERENCES}

[1] T. Bloor, and M. Bloor, The Functional Analysis of English: a Hallidayan Approach, 2nd., London: Hodder Arnold, 2004

[2] S. Eggins, An Introduction to Systemic Functional Linguistics, London: Pinter, 1994.

[3] M. A. K. Halliday, An Introduction to Functional Grammar. London: Edward Arnold, 1994.

[4] G. Thompson, Introducing Functional Grammar (Second Edition). London: Hodder Arnold, 2004.

[5] H. Wei, and G. Wensheng, Syntactic Function Study, Beijing: Foreign Language Teaching and Research Press, 2010.

[6] H. Zhuanglin, Discourse Cohesion and Coherence. Shanghai: Shanghai Foreign Language Education Press, 1994.

[7] H. Guowen, Discourse Analysis Summary. Changsha: Hunan Education Press, 1998. 